\title{
EFEITO DO MÉTODO DE CONDUÇÃO DE POPULAÇÕES SOBRE A SIMILARIDADE GENÉTICA DE UMA POPULAÇÃO SEGREGANTE DE AVEIA, PARA PESO DE PANÍCULA ${ }^{1}$
}

\author{
EFFECT OF SOWING METHOD ON THE GENETIC SIMILARITY \\ OF AN OAT POPULATION SEGREGATING FOR PANICLE WEIGHT
}

\author{
Gaspar MALONE ${ }^{2}$ \\ Volmir Sergio MARCHIORO 3 \\ Paulo Dejalma ZIMMER ${ }^{4}$ \\ Emilia MALONE ${ }^{5}$ \\ Fernando Irajá Felix de CARVALHO 6 \\ Antonio COSTA DE OLIVEIRA ${ }^{6^{*}}$
}

\begin{abstract}
RESUMO
O aumento na eficiência de seleção, o melhor conhecimento e caracterização do germoplasma e a maximização dos ganhos genéticos, têm sido objetivos dos melhoristas de plantas do mundo inteiro. Novas estratégias para alcançar estes objetivos são constantemente implementadas pelo melhoramento de plantas. Os marcadores moleculares oferecem ao melhorista a possibilidade de acessar o genótipo do indivíduo ao invés de apenas o fenótipo. A seleção com base no genótipo pode ser de fundamental importância no estudo e compreensão da função e comportamento de caracteres quantitativos, de difícil avaliação fenotípica. O presente trabalho foi realizado com o objetivo de analisar o efeito de dois métodos de condução de populações sobre a similaridade genética em uma população segregante de aveia, para o caráter peso de panícula. Um total de 23 blocos segregantes para peso de panícula em aveia, na geração $\mathrm{F}_{3}$, conduzidos mediante os métodos de semeadura em cova e planta espaçada, foram analisados mediante a técnica de marcadores moleculares AFLP. Análises de similaridade genética e agrupamento foram realizados utilizando o programa computacional NTSyS pc 2.1. Dos resultados obtidos, com base na similaridade genética, pode-se inferir de que a pressão de seleção exercida nas gerações iniciais não foi suficientemente significativa para modificar o acervo genético da população, quando conduzida mediante os métodos de condução de populações em cova e planta espaçada.
\end{abstract}

Palavras-chave: Similaridade genética; marcadores moleculares; populações segregantes; condução de populações; Avena sativa $L$.

\section{ABSTRACT}

Increase in selection efficiency, the best knowledge and characterization of the germplasm and maximization of the genetic gains, have been objectives of plant breeders worldwide. New approaches to reach these objectives are constantly implemented by breeding programs. Molecular markers allow the breeder to assess individual genotypes instead of just phenotypes. Selection based in the genotype can be of fundamental importance to understand the function and behavior of Quantitative Trait Loci (QTLs), of difficult phenotypic analysis. This work was carry out with the objective of analyzing the effect of two sowing systems (hill and spaced plant) on the molecular genetic similarity in a segregant population for panicle weight in oat. A total of $23 \mathrm{~F}_{3}$ segregant bulks, driven by two sowing systems, were analyzed with AFLP markers. Genetic similarity and grouping analyses were accomplished using the NTSyS pc 2.1 program. Of the obtained results, based in the molecular genetic similarity, we can infer that the selection pressure exercised in the initial generations was not sufficient to modify the genetic composition of the populations, when driven by hill and spaced plant sowing systems.

Key-words: Genetic similarity; molecular markers; segregant populations; sowing systems; Avena sativa L.

\footnotetext{
${ }^{1}$ Parte da dissertação de mestrado em Agronomia, PPGA/UFPel, do primeiro autor;

${ }^{2}$ Geneticista, Doutor em Ciência e Tecnologia de Sementes, Pesquisador em Biotecnología, DON MARIO SEMILLAS, Ruta Nac. 7, Km 208 - C.P 6740, Chacabuco, Provincia de Buenos Aires, Argentina. E-mail: gmalone@donmario.com. Autor para correspondência;

${ }^{3}$ Eng. Agr. Doutor em Fitomelhoramento, Pesquisador em Trigo, COODETEC. E-mail: volmir@coodetec.com.br;

${ }^{4}$ Eng. Agr. Doutor em Ciência e Tecnologia de Sementes. Professor Adjunto do Departamento de Fitotecnia, FAEM/UFPel. E-mail: djzimmer@ufpel.edu.br;

${ }^{5}$ Geneticista, M.Sc. em Biotecnología Agricola. Estudante de Doutorado em Biotecnologia Agricola, CENBIOT/UFPel. Bolsista CAPES. E-mail: emimalone@hotmail.com;

${ }^{6}$ Eng. Agr. PhD, Professor do Centro de Genomica e Fitomelhoramento, Departamento de Fitotecnia, FAEM. UFPel. E-mail: acosta@ufpel.edu.br. * Endereco atual: Department of Genetics, University of Georgia, Athens, GA, USA, 30602.
} 


\section{INTRODUÇÃO}

A maioria dos caracteres de importância agronômica e componentes do rendimento são caracteres de natureza quantitativa, ou seja, governados por vários genes com pequeno efeito $e$ altamente influenciados pelo ambiente. Além disso, apresentam segregação contínua, formando um grande número de classes fenotípicas, o que aumenta a dificuldade de distinção das classes. Regiões genômicas contendo locos gênicos associados a caracteres quantitativos são denominadas Quantitative Trait Loci (QTLs). A habilidade de detectar QTLs por meio de marcadores moleculares é função da magnitude do efeito do QTL, da pressão de seleção e do tamanho da população em estudo.

O peso de panícula em aveia inclui a combinação de dois dos três componentes do rendimento de grãos: grãos por panícula e peso de grãos. Correlações significativas entre o peso de panícula e o rendimento de grãos $(0,54$ e 0,84$)$ têm sido encontradas avaliando a relação entre o peso de panícula, rendimento de grãos e seus componentes em aveia (CAIERÃO et al., 2001; KUREK et al., 2001; BENIN et al., 2003; MARCHIORO et al., 2003). Segundo SAMPSON (1971), o peso da panícula em aveia tem grande potencial para a seleção indireta de linhas superiores em gerações segregantes; contudo, para que o sucesso seja alcançado a seleção deverá ser realizada à campo e sobre plantas com espaçamento reduzido e alta competitividade. Nestas condições, outros trabalhos também revelaram aumento no rendimento de grãos em gerações segregantes, pela seleção indireta de componentes do rendimento, em trigo (MCNEAL et al., 1978), cevada (VALENTINE, 1983) e arroz (GRAVOIS e MCNEW, 1993).

A metodologia de análise por blocos segregantes - Bulk Segregant Analysis (BSA), proposta por MICHELMORE et al. (1991), tem contribuído muito para o estudo de populações segregantes. A metodologia BSA maximiza a escolha de regiões genômicas associadas com um determinado caráter sendo que combina várias constituições genéticas. Por sua vez, a técnica de AFLP-Amplified Fragment Length Polymorphism (VOS et al., 1995) destaca-se pelo abundante polimorfismo que detecta ao nível do genoma completo. Com isso, a combinação de uma técnica de marcadores moleculares com excelente capacidade de detectar polimorfismo, como no caso do AFLP, associado à análise de blocos segregantes, poderá ser muito útil, principalmente para a escolha de constituições genéticas promissoras em populações segregantes de aveia quando conduzidos por diferentes métodos de condução de populações.

Com base em que diferentes métodos de condução de populações exercem diferentes pressões de seleção, aumentando e/ou diminuindo o efeito do ambiente sob a expressão fenotipíca de características quantitativas, a participação do genótipo e a acumulação de genes, ou de regiões genômicas, associadas com a expressão de uma determinada característica, poderão variar em função da interação método de condução/ambiente.

No presente trabalho, 23 blocos segregantes, foram conduzidos mediante os métodos de semeadura em cova e planta espaçada e analisados através da técnica de marcadores moleculares AFLP com o objetivo de estudar o efeito de dois métodos de condução sobre a similaridade genética de populações provenientes de uma população segregante para peso de panícula em aveia.

\section{MATERIAL E MÉTODOS}

No ano agrícola de 2000, uma população segregante de aveia na geração $F_{3}$, proveniente do cruzamento dos genitores UFRGS $14 \times$ OR 2, com alto e baixo peso de panícula respectivamente, foi conduzida em dois métodos de semeadura: cova e planta espaçada. No método de semeadura em cova, as parcelas foram compostas de dez covas, com espaçamento de $45 \mathrm{~cm}$ entre elas e 15 sementes por cova. No método de semeadura em planta espaçada, as parcelas foram compostas de dez linhas de $2 \mathrm{~m}$ de comprimento com espaçamento de $20 \mathrm{~cm}$ entre linhas e $20 \mathrm{~cm}$ entre plantas, totalizando 10 plantas por linha. $O$ delineamento utilizado no experimento foi o de blocos casualizados, com duas repetições. O experimento foi colocado no campo experimental do Centro de Genômica e Fitomelhoramento (CGF) da Faculdade de Agronomia Eliseu Maciel - UFPel.

A viabilidade do lote de sementes utilizadas foi previamente analisada através do teste de germinação padrão (BRASIL, 1992), revelando germinação acima de $80 \%$. Consequentemente, a percentagem de sementes emergidas foi similar nos dois tratamentos.

Após a maturação, todas as panículas, nos dois métodos de semeadura, foram colhidas. As panículas foram pesadas e as com peso superior à média mais um desvio padrão, assim como as com peso inferior à média menos um desvio padrão, dentro de cada cova e dentro de cada linha de planta espaçada foram selecionadas.

Depois de trilhadas as panículas selecionadas, as sementes foram agrupadas em blocos (bulks), formando pares com as panículas mais pesadas e outros com as mais leves dentro de cada cova e dentro de cada linha de planta espaçada (Tabela 1). Em 2003 as sementes de cada um dos 23 tratamentos e mais os genitores foram semeadas para extração de DNA. Por ocasião da formação da segunda folha uma pequena amostra de folha de dez plantas, de cada um dos 25 tratamentos foi coletada. Essas amostras foram submetidas à extração de DNA, utilizando o método descrito por STEIN et al. (2001). 
TABELA 1 - Relação dos blocos segregantes formados com a seleção para o peso de panícula da população de aveia UFRGS $14 \mathrm{x}$ OR 2 nos dois métodos de semeadura e mais os genitores.

\begin{tabular}{cccc}
\hline & TRATAMENTO & & TRATAMENTO \\
\hline 1 & Seleção cova - superior & 13 & Seleção planta espaçada - superior \\
2 & Seleção cova - inferior & 14 & Seleção planta espaçada - inferior \\
3 & Seleção cova - superior & 15 & Seleção planta espaçada - superior \\
4 & Seleção cova - inferior & 16 & Seleção planta espaçada - superior \\
5 & Seleção cova - superior & 17 & Seleção planta espaçada - inferior \\
6 & Seleção cova - inferior & 18 & Seleção planta espaçada - superior \\
7 & Seleção cova - superior & 19 & Seleção planta espaçada - inferior \\
8 & Seleção cova - inferior & 20 & Seleção planta espaçada - superior \\
9 & Seleção cova - superior & 21 & Seleção planta espaçada - inferior \\
10 & Seleção cova - inferior & 22 & Seleção planta espaçada - superior \\
11 & Seleção cova - superior & 23 & Seleção planta espaçada - inferior \\
12 & Seleção cova - inferior & & Genitor - UFRS 14 \\
& & & Genitor - OR 2 \\
\hline
\end{tabular}

A técnica AFLP foi utilizada para analisar os 23 blocos segregantes e mais os genitores, de acordo com o protocolo fornecido pelo fabricante (Life technologies - GIBCO $\left.{ }^{\circledR}\right)$. Um total de 24 combinações de primers foram utilizadas.

Ao produto de amplificação foi adicionado $2 / 3$ do seu volume de tampão de carga $(98 \%$ formamida, 10 mM EDTA pH 8.0, azul de bromofenol e xileno cianol), seguido de desnaturação a $94 \stackrel{\circ}{\mathrm{C}}$ durante 6 minutos e aplicação no gel de acrilamida $6 \%$ em condições desnaturantes. A corrida eletroforética foi realizada em cuba de sequenciamento manual modelo HOEFER SQ3 Sequencer. A revelação dos fragmentos amplificados foi realizada de acordo com o protocolo de coloração com nitrato prata (BRIARD et al., 2000).

Todos os marcadores polimórficos entre os genitores da população segregante foram avaliados para presença (1) e ausência (0) nos 23 blocos segregantes. Os dados foram utilizados para a construção de uma matriz binária para análise. As análises de similaridade genética, matriz cofenética, comparação de matrizes e análise de agrupamento foram realizadas utilizando o programa computacional NTSyS pc 2.1 (ROHLF, 2000). A similaridade genética foi estimada usando o coeficiente de NEI e LI (1979). As variâncias e as médias foram estimadas para as duas matrizes de similaridade e comparadas as médias pelo teste $t$ (BEINGUELMAN, 2002). A similaridade genética média foi utilizada como ponto de corte para a formação dos grupos. Os 23 blocos foram agrupados com base na matriz de similaridade genética utilizando o método UPGMA (Unweighted Pair-Group Method with arithmetic Averages).

\section{RESULTADOS E DISCUSSÃO}

Da análise AFLP utilizando as 24 combinações de primers, foram obtidos um total de 218 marcadores polimórficos. O número de marcadores polimórficos variou de um máximo de 18 para a combinação de primer Msel-CTT; EcoRI-ACA até um mínimo de 4 para a combinação Msel-CAC; EcoRI-ACC.

Método de semeadura em cova: A similaridade genética entre os blocos segregantes, quando conduzidos pelo método de semeadura em cova, esteve compreendida entre 0,51 e 0,76. O valor da matriz cofenética (r) (ROHLF e SOKAL, 1981), obtida da comparação das matrizes de similaridade e do dendrograma foi de 0,86 . Esse valor, considerado altamente representativo, reflete a precisão do dendrograma na representação gráfica dos dados de similaridade entre os genótipos. No entanto, com base na similaridade genética média para a formação dos agrupamentos, não foi possível estabelecer associações importantes entre os blocos segregantes e o caráter peso de panícula. Os possíveis grupos de genótipos mais similares ficaram conformados por blocos segregantes de elevado e de baixo peso de panícula (Figura 1). 
MALONE, G. et al. Efeito do método de condução...

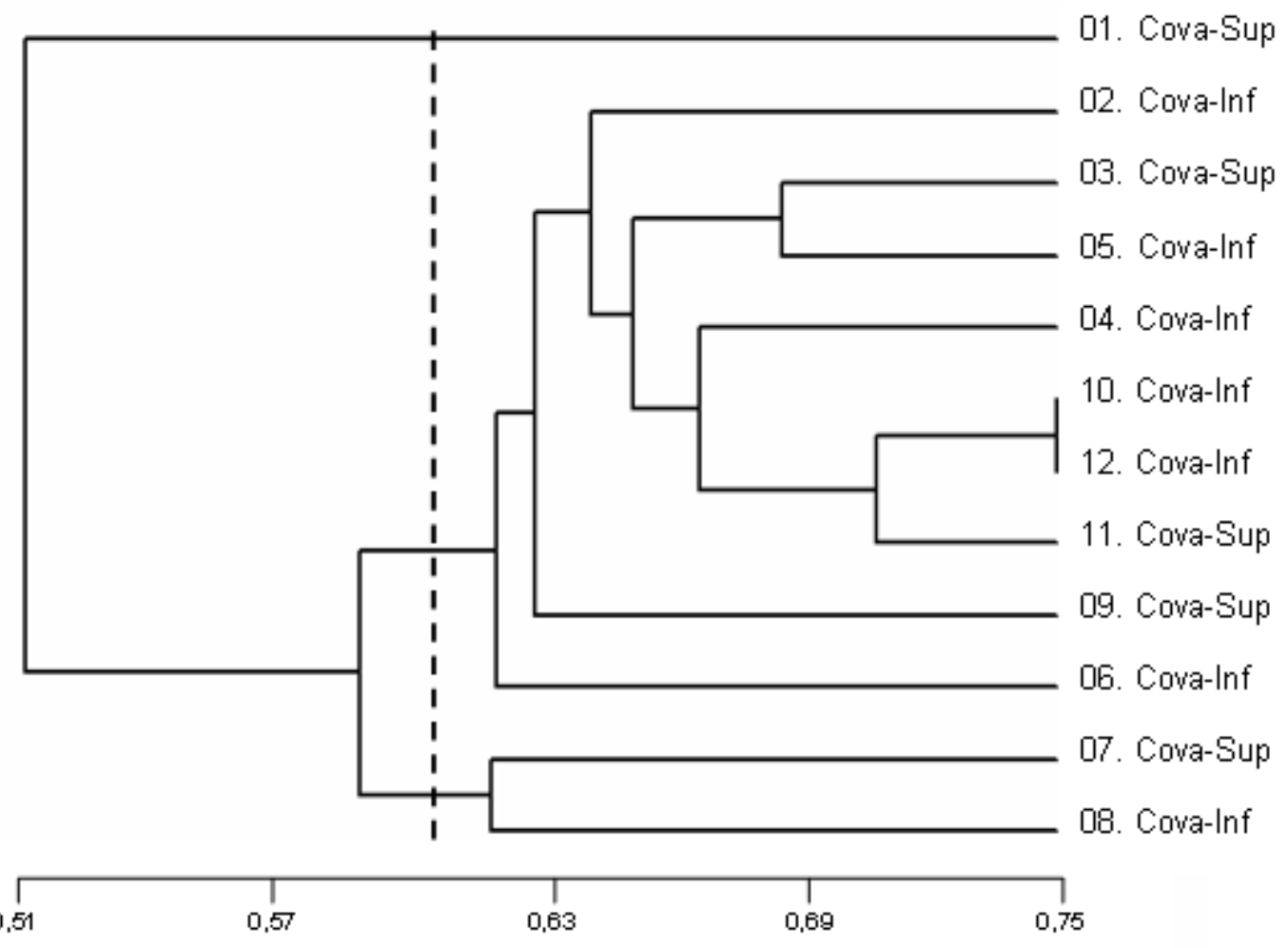

Similaridade genética

\section{- - - Similaridade genética média}

Cova-Inf.: Bloco segregante, na geração $\mathrm{F}_{3}$, selecionado para peso de panícula inferior a média.

Cova-Sup.: Bloco segregante, na geração $\mathrm{F}_{3}$, selecionado para peso de panícula superior a média.

FIGURA 1 - Dendrograma obtido com base em marcadores moleculares AFLP utilizando o método de agrupamento UPGMA, para os dados de plantas conduzidas pelo método em cova de uma população segregante de aveia para peso de panícula.

Método de semeadura por planta espaçada: A similaridade genética entre os blocos segregantes, quando conduzidos pelo método de semeadura em planta espaçada, esteve compreendida entre 0,62 e 0,83 . O valor da matriz cofenética (r) (ROHLF e SOKAL, 1981), obtida da comparação das matrizes de similaridade e do dendrograma, embora mais baixo que o obtido com o método de semeadura em cova, foi de 0,77 . Esse valor, considerado representativo, reflete a precisão do dendrograma na representação gráfica dos dados de similaridade dentre os genótipos. Da mesma forma que aconteceu com o método de condução em cova, a similaridade genética calculada entre os blocos segregantes conduzidos pelo método de planta espaçada não permitiu realizar uma boa associação entre o caráter peso de panícula e os blocos segregantes. A similaridade genética média foi utilizada como ponto de corte na formação dos grupos (Figura 2).

Da análise de comparação de médias pelo teste $t$ entre as duas matrizes de similaridade, para ambos os métodos de semeadura, obteve-se um valor de 0,75 indicando que elas não diferem significativamente a $1 \%$ de significância. Isso pode ser em função de que os blocos segregantes, conduzidos mediante os dois métodos de condução de populações, serem decorrentes do mesmo cruzamento.

Os dados decorrentes das análises de agrupamentos com base em dados moleculares não concordam com os postulados de SAMPSON (1971), em que o peso de panícula em aveia tem grande potencial para a seleção indireta de linhas superiores em gerações segregantes, desde que a seleção seja realizada a campo e sobre plantas com espaçamento reduzido (alta competitividade). De acordo com GEADELMANN e FREY (1975), o efeito da seleção direta ou indireta para rendimento de grãos encontrado em um ambiente competitivo, onde ocorra seleção natural, promove um ganho de seleção maior em relação a ambientes não competitivos (plantas espaçadas). No entanto, os resultados obtidos neste trabalho evidenciaram que a base genética da população segregante manteve-se mais estreita quando conduzida pelo método de planta espaçada, em ambiente não competitivo (entre 0,62 e 0,83), comparada com a base genética da população segregante conduzida pelo método em cova (entre 0,51 e 0,76 ). Além disso, os valores de similaridade genética média no método de condução em cova $(0,60)$ foi menor que no método por planta espaçada 
$(0,67)$, evidenciando que, embora sobre condições de baixa competitividade, os blocos segregantes mantiveram-se mais similares geneticamente que em condições de elevada competitividade entre plantas. Contudo, as análises de agrupamento de blocos segregantes com base na similaridade genética molecular revelaram que não há variação significativa no acervo genético das populações na geração $F_{3}$, quando conduzidas mediante os métodos de condução de populações em cova e planta espaçada.
Provavelmente, a seleção exercida sobre as populações não foi suficiente para ocasionar uma segregação significativa de genes que possibilitaria a separação dos blocos conduzidos pelos dois métodos de semeadura. Além disso, o caráter peso de panícula sofre uma significativa participação do ambiente na expressão fenotípica, o que dificulta a identificação de constituições genéticas, ou blocos segegantes, mediante marcadores moleculares em gerações iniciais.

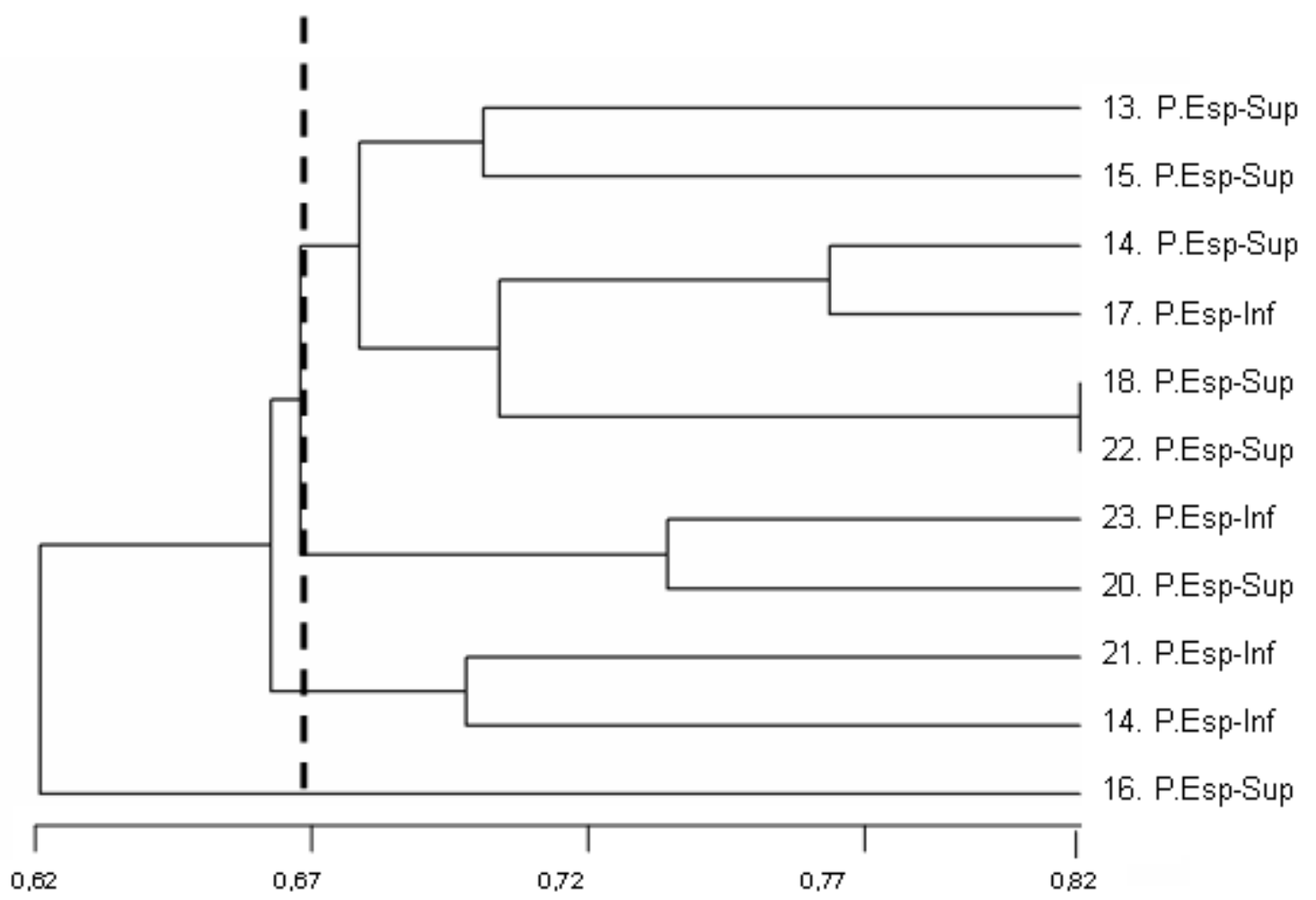

Similaridade Genética

- - - Similaridade genética média

Cova-Inf.: Bloco segregante, na geração $\mathrm{F}_{3}$, selecionado para peso de panícula inferior a média.

Cova-Sup.: Bloco segregante, na geração $\mathrm{F}_{3}$, selecionado para peso de panícula superior a média.

FIGURA 2 - Dendrograma obtido com base em marcadores moleculares AFLP utilizando o método de agrupamento UPGMA, para os dados de plantas conduzidas pelo método de planta espaçada de uma população segregante de aveia para peso de panícula.

\section{CONCLUSÕES}

- A dissimilaridade genética entre os blocos segregantes conduzidos mediante os métodos de semeadura em cova e planta espaçada.

- A pressão de seleção exercida não foi suficiente para ocasionar uma segregação que proporcionasse a acumulação de genes distintos para cada método de semeadura. 
MALONE, G. et al. Efeito do método de condução...

\section{REFERÊNCIAS}

1. BEINGUELMAN, B. Curso prático de bioestatística. 5. ed. Ribeirão Preto: Fundação de pesquisas cientificas de Ribeirão Preto, 2002.

2. BENIN, G; CARVALHO, F.I.F. de.; OLIVEIRA, A.C. de.; MARCHIORO, V.S.; LORENCETTI, C.; KUREK, A.J.; SILVA, J.A.G.; CARGNIN, A.; SIMIONI, D. Estimativas de correlações e coeficientes de trilha como critérios de seleção para rendimento de grãos em aveia. Revista Brasileira de Agrociência, Pelotas, v. 9, n. 1, p. 9-16, 2003.

3. BRASIL. Ministério da Agricultura e da Reforma Agrária. Regras para análise de sementes. Brasília: SNDA/DNDV/CLAV, 1992. $365 \mathrm{p}$.

4. BRIARD, M.; LE CLERC, V.; GRZEBELUS, D.; SENALIK, D.; SIMON, P.W. Modified protocols for rapid carrot genomic DNA extraction and AFLPTM analysis using silver stain on radioisotopes. Plant Molecular Biology Reporter, v. 18, p. 235-241, 2000.

5. CAIERÃO, E.; CARVALHO, F.I.F. de.; PACHECO, M.T.; LORENCETTI, C.; MARCHIORO, V.S.; SILVA, J.A.G.; Seleção indireta em aveia para o incremento no rendimento de grãos. Ciência Rural, Santa Maria, v. 31, n. 2, p. 231-236, 2001.

6. GAEDELMANN, J.L.; FREY, K.J. Direct and indirect mass selection for grain yield in bulk oat populations. Crop Science, Madison, v. 15, p. 190-194, 1975

7. GRAVOIS, K.A.; MCNEW, R.W. Genetic relationships among and selection for rice yield and yield components. Crop Science, Madison, v. 33, p. 249-252, 1993.

8. KUREK, A.J.; CARVALHO, F.I.F.; ASSMANN, I.C.; MARCHIORO, V.S.; CRUZ, P.J. Análise de trilha como critério de seleção indireta para rendimento de grãos em feijão. Revista Brasileira de Agrociência, Pelotas, v. 7, n. 1, p. 29-32, 2001.

9. MARCHIORO, V.S.; CARVALHO, F.I.F.; OLIVEIRA, A.C.; LORENCETTI, C.; BENIN, G; SILVA, J.A.G.; KUREK, A.J.; HARTWIG, I. Herdabilidade e correlações para caracteres de panícula em populações segregantes de aveia. Revista Brasileira de Agrociência, Pelotas, v. 9, n. 4, p. 323-328, 2003.

10. McNEAL, F.H.; QUALSET, C.O..; BALDRIGE, D.E.; STEWART E.R. Selection for yield and yield components in wheat. Crop Science, Madison, v. 18, p. 795-799, 1978.

11. MICHELMORE, R.W.; PARAN, I.; KESSELI.; R.V. Identification of markers to disease-resistance genes by bulked segregant analyses: a rapid method detect markers in specific genomic regions by using segregating populations. Procedings National Academic Sciences, USA, v. 88, p. 9828-9832, 1991.

12. NEI, M.; LI, W.H. Mathematical model for studying genetic variation in terms of restriction endonucleases. Procedings National Academic Sciences, USA, v. 76, p. 5269-5273, 1979.

13. ROLHF, F.J. NTSYS-pc: Numerical taxonomy and multivariate analysis system. Version 2.1. New York: Exeter Publications, 2000.

14. ROHLF, F.J.; SOKAL, R.R. Comparing numerical taxonomic studies. Systematic zoology, v. 30, p. 459-490, 1981.

15. SAMPSON, D.R. Additive and non additive genetic variances and genotype correlations for yield and other traits in oats. Canadian Journal Genetics Cytology, Ottawa, v. 13, p. 864-872, 1971.

16. STEIN, N., HERREN, G.; KELLER, B. A new DNA extraction method for high-throughput marker analysis in a large-genome species such as Triticum aestivum. Plant Breeding, v. 120, n. 4, p. 354-356. 2001.

17. VALENTINE, J. Early generation selection for yield in cereals. In: LANGE, W. Efficiency in plant breeding. In: EUROPEAN CONGRESS OF RESOURCES PLANT BREEDING, 10., Wageningen, 1983. Proceedings. Wageningen: Eucarpia, 1983.

18. VOS, P.; HOGERS, R.; BLEEKER, M.; REIJANS, M.; VAN DE LEE, T.; HORNES, M.; FRIJTERS, A.; POT, J.; PELEMAN, J.; KUIPER, M. AFLP: a new technique for DNA fingerprinting. Nucleic Acids Research, v. 23, n. 21, p. 4407-4414, 1995.

Recebido em 15/08/2005

Aceito em 04/04/2007 